\title{
Risk determinants of small and medium-sized manufacturing enterprises (SMEs) - an exploratory study in New Zealand
}

\author{
Ariful Islam ${ }^{1 *}$ and Des Tedford ${ }^{2}$
}

\begin{abstract}
The smooth running of small and medium-sized manufacturing enterprises (SMEs) presents a significant challenge irrespective of the technological and human resources they may have at their disposal. SMEs continuously encounter daily internal and external undesirable events and unwanted setbacks to their operations that detract from their business performance. These are referred to as 'disturbances' in our research study. Among the disturbances, some are likely to create risks to the enterprises in terms of loss of production, manufacturing capability, human resource, market share, and, of course, economic losses. These are finally referred to as 'risk determinant' on the basis of their correlation with some risk indicators, which are linked to operational, occupational, and economic risks. To deal with these risk determinants effectively, SMEs need a systematic method of approach to identify and treat their potential effects along with an appropriate set of tools. However, initially, a strategic approach is required to identify typical risk determinants and their linkage with potential business risks. In this connection, we conducted this study to explore the answer to the research question: what are the typical risk determinants encountered by SMEs? We carried out an empirical investigation with a multi-method research approach (a combination of a questionnaire-based mail survey involving 212 SMEs and five in-depth case studies) in New Zealand. This paper presents a set of typical internal and external risk determinants, which need special attention to be dealt with to minimize operational risks of an SME.
\end{abstract}

Keywords: SMEs, disturbance, Risk, Risk determinants, Strategic risk management

\section{Background}

In the dynamic and highly competitive business environment, manufacturing industries are under tremendous pressure due to the free market economy, rapid technological development, and continuous changes in customer demands (Islam et al. 2006). To cope with the current business trends, the demands on modern manufacturing systems have required increased flexibility, higher quality standards, and higher innovative capacities (Monica and John 1999). 'These demands emphasize the need for high levels of overall system reliability that include the reliability of all human elements, machines, equipment, material handling systems and other value added processes and management functions throughout

\footnotetext{
* Correspondence: arifbd@yahoo.com

'Department of Industrial and Production Engineering, Shahjalal University of Science and Technology, Sylhet 3114, Bangladesh

Full list of author information is available at the end of the article
}

the manufacturing system' (Islam et al. 2006). Whatever the resources they possess, the manufacturing organizations encounter undesirable events and unwanted setbacks such as machine breakdowns, material shortages, accidents, and absenteeism that make the system unreliable and inconsistent (Monica and John 1999; Islam 2008; Islam et al. 2008; Mitala and Pennathurb 2004; Monostori et al. 1998; Toulouse 2002). In fact, undesirable events and unwanted setbacks (internal and external) in day-to-day operations are common in small and medium-sized manufacturing enterprises (SMEs; Islam 2008). The authors of this paper chose the word 'disturbance' to represent any of these undesirable events and setbacks. They define the disturbance as 'an undesirable or unplanned event that causes the deviation of system performance in such a way that it incurs a loss,' and the definition is published by the authors elsewhere (Islam et al. 2006; Islam 2008). This research adopts the 
definition of disturbance. As a disturbance creates undesirable consequences that are obviously detrimental to a business performance, we finally refer to a disturbance as a 'risk determinant' on the basis of its significant presence in the system and its consequential negative impact on business and operational performance. Disturbances are linked to undesirable consequences which may originate from different circumstances (Monostori et al. 1998). 'Whatever the sources of disturbances, the consequences resulting from them could be; difficulties to continue work, decreased productivity, reduced production rate, increased defective products, unplanned rework, delayed delivery to market, unexpected downtime, human loss, etc.' (Islam et al. 2006; Islam 2008). In practice, there is a financial loss due to any consequential effects of disturbances. The combined effect of different disturbances could effectively cripple an SME's business performance which may ultimately put it at risk of complete failure (Islam et al. 2006). The risks can, in general, be categorized into three groups: operational, occupational, or economic. The first category of risks involves the loss of production and the loss of production capability that includes productivity losses, qualityrelated losses, interrelated activity losses, and asset losses. The second category comprises the risks associated with employees' health, safety, and well-being, while the third category encompasses business risks associated with the financial penalties resulting from either of the first two categories as well as compensation claims and damage to reputation. While dealing with risks, the term 'hazard' automatically comes into the scenario; thus, the definition of a hazard can play an important role when dealing with risks in the industrial context. A hazard is a condition that can cause harm, injury, death, damage, or loss of equipment or personnel (Bahr 1997) and can exist without anything actually failing within the enterprise. There are four types of hazards, namely catastrophic (death or serious personnel injury or loss of a complete system), critical (severe injury or loss of valuable equipment), minor (minor injury or minor system damage), and negligible (no resulting significant injury or system damage). While examining the definitions of a hazard, it can be noticed that a hazard ultimately represents a situation or condition that has the potential to harm people, property, or the environment. However, a question now presents itself, that if there is no chance to harm any of these three elements (people, property, environment), can we classify the situation as a hazard? For an example, the absence of a key machine operator may have no impact on any of these three elements, but it has the potential to develop financial risk to the organization in terms of loss of production; however, the impact might be severe for a small business if the absence is prolonged. There might be some debate as to whether absenteeism should be included in the hazard category or not, but most people would agree to recognize it as a potential operational disturbance which could have serious consequences for an SME. Operational disturbances can be seen from different perspectives and can also be described with various words such as disruptions, failures, errors, defects, losses, and waste (Islam 2008). However, all potential disturbances and their consequential losses should be considered in the risk management of SMEs because they can be both time-consuming and costly. We believe that this type of disturbance should be studied under the umbrella of risk management. Consequently, while studying risk management in SMEs, we prefer to use the term 'disturbance' instead of hazard. According to our definition, therefore, a disturbance represents all types of hazards as well any other unwanted setback that can produce uncertainty or a loss for an organization.

The focus of our research was to identify typical risk determinants of SMEs that need to be considered in developing an integrated risk management approach which should include strategic, operational, occupational, financial, and technology-oriented risks. The research is, therefore, built in a specific research question - what are the typical risk determinants of manufacturing SMEs?

Based on the findings related to the question, we have identified a set of key internal and external operational disturbances, which are eventually highlighted as 'risk determinants' based on their occurrence and consequential effects on the business performance of SMEs. This paper presents the identified risk determinants and describes a methodology to identify them.

SMEs are viewed as a source of flexibility and innovation, and they make significant contributions to the economies of many countries, both in terms of the number of SMEs and the proportion of the labor force employed by them (Hoffman et al. 1998; Ministry of Economic Development 2004). However, SMEs are perceived as high-risk ventures, and the entry and exit rates support this perception (Zacharakis et al. 1999). Previous research has indicated that there is little difference between small business failure rates in developed and developing economies, and it is estimated that $50 \%$ of all start-ups fail in their first year, while $75 \%$ to $80 \%$ fail within the first 3 to 5 years in the USA (Anderson and Dunkelberg 1990). It has also been shown that up to $50 \%$ of the small businesses started in South Africa eventually failed (Watson and Vuuren 2002). In New Zealand, $40 \%$ to $50 \%$ of small businesses failed within the first 10 years, and a negative correlation was found between a firm's total full-time employment and its failure rate (Ministry of Economic Development 2004). Business failure is often caused by a lack of knowledge, 
misplaced overconfidence, lack of financial performance strategies, or a lack of internal management planning (Gibson and Cassar 2005; Hartcher et al. 2003). In spite of high failure rates, however, small businesses continue to be an essential component of the economy of many countries as they account for a significant percentage of all entities and collectively employ large numbers of the workforce. Generally, SMEs depend on financial factors such as profit or sales when considering business risks (Waring and Glendon 1998). However, monetary factors alone may ignore many issues affecting the long-term reputation of the SME and its staff. A recent research study has suggested that risk management is less well developed within SMEs where the strong enterprise culture sometimes mitigates against managing risks in a professional structured way (Virdi 2005). According to the study, the SMEs are reluctant to adopt a formal risk management strategy despite having the evidence that businesses that adopt risk management strategies are more likely to survive and grow. Zacharakis et al. (1999) identify some reasons for failures of small businesses that include both internal and external causes. The internal causes of failure include poor management, lack of risk management planning, and failure to adopt a risk limit threshold. The external causes included government policies, the vulnerability resulting from small size, competition from larger businesses, civil strife, natural disasters, and general economic downturns. It was also found that 'overconfidence' could often drive small business operators to devalue the importance of fundamental risk assessment that ultimately caused their failure. Although there are some other causes for failure that are highlighted in this section, our research is not intended to investigate the reasons behind the absolute failures of SMEs. Rather, it deals with identifying the potential risks existing when operating SMEs within their current infrastructures so that they can avoid potential failures by implementing a strategic risk management approach. Because manufacturing involves a complicated mix of people, systems, processes, and equipment, an effective research strategy needs to be multidisciplinary in its approach to establishing a risk management framework (Islam 2008). Because of some infrastructural, technological, financial, and human resource-related limitations, SMEs may keep themselves away from adopting a positive approach towards strategic risk management (Islam et al. 2006; Islam 2008; Hartcher et al. 2003; Martie-Louise 2006). Islam et al. (2006) state:

It is noteworthy to mention that major accidents and emergencies rarely occur in SMEs although small losses, near misses, unsafe acts and unsafe conditions are common occurrences. But, problems, failures and mistakes as well as incorrect or ineffective actions, are very likely occurrences in the daily business of SMEs and for this reason, in practice, minor incidents and near misses are worth analyzing since in slightly different circumstances the consequences could have been quite serious. By monitoring even small problems and analyzing their underlying causes, it might be possible to discover causes for more serious problems and the existence of hazards. Therefore, no disturbance should be overlooked or should be allowed to happen again.

In the authors' knowledge, research works done on risk management have generally focused on particular industries such as nuclear, aviation, space exploration, chemical processing, and other areas where the consequence of a system breakdown is considered severe or catastrophic for human beings or the environment, and/ or where the potential financial loss is significant (Islam et al. 2006; Andrews and Moss 2002; Khan and Abbasi 1998; Milan 2000; Seastroma et al. 2004; Strupczewski 2003). In addition, research works on risk management in other areas, including financial sectors, medical science, transportation, and construction engineering, have also significantly expanded with time (Islam et al. 2006). In contrast to this, lower priority has been noticed in the literature concerning risk management in the SME sector. Most of the studies relevant to risk management in this sector indeed concentrate solely on the risks associated with safety and occupational health (Islam et al. 2006; Islam 2008). Protective practices such as occupational safety and health and other safety-related programs should, if properly implemented and practiced, ensure better health and working environments inside organizations. They do not, however, ensure the smooth running of the organization or minimize its risks operationally, technically, and/or financially.

Hazard identification within a system is the starting point of any risk identification or assessment process that emphasizes the critical components or factors that produce or could produce failure or harmful consequences for humans, assets, or the environment (Islam et al. 2006; Islam 2008). In this context, different techniques such as Hazard and Operability Analysis studies, Failure Mode and Effect Analysis, Failure Mode and Effect Critical Analysis, Hazard Analysis with Critical Control Points, Fault Tree Analysis, Event Tree Analysis, 'What if' analysis, and Checklists are widely used in practice (Islam et al. 2006; Khan and Abbasi 1998; Mushtaq and Chung 2000; Pearson and Dutson 1995; Tixier et al. 2002). All these techniques focus on the main hazard sources systematically, but none of them can produce a thorough list of important system failures, causes, consequences, and controls and can lend themselves to rigorous risk acceptability analysis (Islam et al. 2006). Furthermore, none of the techniques are necessarily effective in identifying and prioritizing the risks associated with multifaceted criteria. None of the 
abovementioned methods alone can readily be applicable for dealing with risks associated with operational disturbances, because of their complex nature. 'For example, a disturbance such as 'tool shortage' could be rooted in; erroneous planning of stock, misuse by the operator, unexpected breakage, or incorrect selection of tool for the particular task. Thus, the origin of the disturbance could either be strategic, operational or technical. This means that a detailed analysis of a particular disturbance is required to establish a suitable risk handling procedure' (Islam et al. 2006). In this connection, we have developed a strategic risk management model for SMEs and have published the model elsewhere (Islam et al. 2006; Islam et al. 2008). However, we conducted further study on the identification of specific risk determinants of SMEs and have discussed the identified determinates in this paper.

\section{Case description}

\section{Research methodology}

We choose an empirical investigation as it puts special emphasis on the affiliated research leading to the development of a strategic risk management framework in terms of operational and organizational aspects (Islam 2008; Glaser and Strauss 1980; Luis et al. 1999; Mills et al. 1995; Pettigrew et al. 1989). The empirical investigation was carried out by applying a multi-method approach (combination of case study and survey methods), called triangulation, which provided a relatively potent means of assessing the degree of convergence, as well as identifying divergences, between the results obtained (Islam 2008; Brewer and Hunter 2006; Jick 1979). In the triangulation method, the survey results improved the authors' understanding of the particular phenomenon (relationship between potential disturbances and their associated risks in this case). On the other hand, the case studies added to a more holistic and richer contextual understanding of the survey results. Thus, the multimethod approach is believed to be enhancing the credibility of the research results while reducing the risk of observations reflecting some unique artifact (Brewer and Hunter 2006; Denzin 1989).

\section{Data collection methods and sample}

For the empirical investigation, standard questionnaires were developed and verified by a panel of academic experts and subsequently by an industry focus group in a pilot study. The questionnaires were designed to explore the risk determinants (potential disturbances) and risk indicators (detrimental parameters to business performance) relating to existing practices in the studied organizations. The focal points of the questionnaire were (1) production-related activities associated with risks; (2) quality, reliability, and health- and safety-related issues of both assets and personnel; (3) major activities in the supply chain networks; and finally, (4) strategic issues relating to the current practices in risk management.

There were two phases in the data collection process. In the first phase, questionnaires were sent to 55 manufacturing SMEs (to 165 individual management personnel, to three tiers of management of each organization), and in the second, to 157 SMEs (to 417 management personnel). The respondents were given 1 month to return the completed questionnaires while an additional 3 weeks were allocated for telephoning and personal interviewing to acquire missing data in incomplete questionnaires. Out of 212 SMEs, 11 SMEs declined to participate in the questionnaire survey due to their organizational restructuring, busy scheduling of the management, absorption in other business sectors, or some other undisclosed reasons, though they mentioned their keen interest (in the response letters) to the research subject. Four sets of questionnaires were sent back to the researchers not finding the addressee. Five participating organizations provided partially completed questionnaires, which have been excluded in the analysis. Altogether, 96 usable responses from management personnel (top, middle, and front-line management), from 32 responding SMEs, were returned and have been analyzed, and presented in this paper. It is noted that the organization which returned three sets of completed questionnaire is only considered as responding SME. In this connection, the useful response rate of $18.27 \%$ from companies was considered satisfactory and representative of SMEs in New Zealand. The overall response rate of $23.08 \%$ from the selected SMEs indicates the substantial importance of the research topic, while past experience suggests that mail survey response rates are often low and appear to be declining among small business populations (Dennis 2003). However, before making any conclusive remarks on the survey findings, further verification was carried out by subsequent in-depth case studies involving five SMEs from among the participants in the mail survey. We choose the follow-up case study approach as '. . . an empirical inquiry that investigates a contemporary phenomenon within some real-life context and a methodology involving multiple sources of data which provides the fullest understanding of the phenomenon and improves the validity of research implications through triangulation' (Scudder and Hill 1998; Yin 1994). The case studies were conducted longitudinally over an 8-month period. The findings from the mail survey enabled us to develop a deeper understanding of the existing strategies and underlying practices in typical SMEs in New Zealand. During the case studies, ten elements of the operation, namely premises, product, purchasing, people, procedures, protection, processes, performance, planning, and policy, that represent the main 
risk areas to the success of a business were considered (Jeynes 2002). An ethnographic approach, which involves the sustained participation in, and observation of, the practical business settings which cover the day-to-day incidents and practical phenomena occurring within the organization, was applied in the case studies (Yin 1994; Bowman and Ambrosini 1997; Charmaz 2006). Apart from direct observation, relevant documents and diagrams from the studied organizations were reviewed and verified. Supplementary data were collected through formal interviews (with key senior executives who shape the firms' operations strategy) and informal discussions (with frontline managers, production supervisors, and some key employees on the shop-floor).

\section{Validation of questionnaire}

The mailed survey was carried out by the developed questionnaires. One questionnaire was designed for top management (senior executives), and the other was designed for middle and front-line management of each organization. The purpose of two separate questionnaires was to collect disturbance information from different areas of concerns of each management level. In total, 26 questions were formulated for the questionnaire of the top management and 34 questions were in the questionnaire for middle management. However, in the context of this paper, the questions that were directly related to the disturbances are presented in Additional file 1 for the clarity of the investigation. Most of these questions were of the 'multiple choice' kind. The answers of the questions comprised four-point rating scales for response. The four-point rating scale was chosen to prevent the occurrence of central tendency error.

A typical example of the questions related to an internal disturbance is, Over the last 12 months, how often did you notice 'absenteeism' in your organization? ( 4 = often, 3 =sometimes, 2 =rarely, and 1 =never). A typical example of the questions related to an external disturbance is, To what extent does 'skilled labor shortage' impede your business performance (profit/growth)? $(4=$ to great extent, $3=$ to some extent, $2=\mathrm{a}$ little amount, and $1=$ not at all). A typical example of the questions related to a risk indicator is, Over the last 12 months, how often did you notice 'lower than expected productivity'? ( 4 = often, $3=$ sometimes, 2 = rarely, and 1 = never).

The questionnaires were designed in such a way that they were easy to understand and answer. They were pretested and carried out in two sequential stages. The first stage consisted of a review by a panel of academic experts and survey specialists who ensured that all necessary questions were included and ambiguous questions eliminated, and the categorization of the questions was set up properly to ensure that subsequent data analysis would provide the desired information. The second stage was a pilot study with ten participating SMEs. The responses from the pilot study allowed the authors to verify whether respondents were biased towards certain categories of questions or leaving questions unanswered. The study found that all respondents answered all questions and the responses on the ordinal scales were reasonably dispersed. Finally, the measuring scales were tested to verify the reliability of instrument with the help of Cronbach's alpha $(\alpha)$ (Hinton 2004; Black 1999). The values of $\alpha$ were 0.701 and 0.716 , and 0.721 for the questions of internal and external disturbances, and risk indicators (consequential effect), respectively, that ensured the reliability and internal consistency of the measuring scales.

\section{Characteristics of studied SMEs}

The significance of the SME sector in New Zealand has been increasing, with further opportunities presented by globalization and technological development (Ministry of Economic Development 2004). New Zealand is a small nation state of 4.3 million people, ethnically diverse, with a strong culture of self-help and independence underpinning business development (Ministry of Economic Development 2004). New Zealand's size means that by international standards, its small businesses are very small but are the dominant sector in terms of employment, organizational structure, and social and economic cohesion. A recent report on SMEs states that in the context of policy consideration, the characteristics of small-sized businesses should typically include personal ownership and management, few specialist managerial staff, and not being part of a larger business enterprise (Ministry of Economic Development 2003). SMEs in New Zealand typically exhibit these characteristics, and it is in this context that our research has been designed to deal with companies with employment in the range of 10 to 100 employees (Islam 2008).

The list of SMEs selected for the mail survey and case studies was compiled from a variety of business databases; these were randomly chosen to represent a range of manufacturing groups. These groups covered the four sectors of (1) metal-based product and equipment manufacturers, (2) wood and wood-based product manufacturers, (3) paper- and plastic-based product manufacturers, and (4) textile and garment manufacturers. These groups were selected because of their economic importance to New Zealand. The characteristics of the participating SMEs in the mail survey are presented in Table 1.

\section{Key findings and analysis}

The key findings are categorized and presented in the following sections: 
Table 1 Characteristics of the selected SMEs

\begin{tabular}{|c|c|c|c|}
\hline Classification & Criteria & $\begin{array}{c}\text { Number of } \\
\text { organizations }\end{array}$ & $\begin{array}{c}\text { Percentage of } \\
\text { organizations (\%) }\end{array}$ \\
\hline \multirow[t]{2}{*}{ Firm size } & Small size (10 to 25 employees) & 12 & 37.50 \\
\hline & Medium size (26 to 100 employees) & 20 & 62.50 \\
\hline \multirow[t]{4}{*}{ Annual turnover (New Zealand \$) } & Less than 5 million & 4 & 12.50 \\
\hline & Between 5 and 25 million & 20 & 62.50 \\
\hline & Between 25 and 50 million & 6 & 18.75 \\
\hline & Over 50 million & 2 & 6.25 \\
\hline \multirow[t]{4}{*}{ Business category } & Metal-based product and machinery manufacturing & 16 & 50.00 \\
\hline & Textile and garment manufacturing & 6 & 18.75 \\
\hline & Wood-based product and furniture manufacturing & 6 & 18.75 \\
\hline & Plastic- and paper-based product manufacturing & 4 & 12.50 \\
\hline \multirow[t]{3}{*}{ Plant set-up } & Single site & 20 & 62.50 \\
\hline & Multi-domestic sites & 9 & 28.13 \\
\hline & Multinational sites & 3 & 9.38 \\
\hline \multirow[t]{4}{*}{ Employment contracts } & Nil & 11 & 34.38 \\
\hline & Less than $5 \%$ of total employees & 17 & 53.13 \\
\hline & Between $5 \%$ and $10 \%$ of total employees & 2 & 6.25 \\
\hline & More than $10 \%$ of total employees & 2 & 6.25 \\
\hline \multicolumn{2}{|l|}{ Total number of selected organizations } & 32 & 100.00 \\
\hline
\end{tabular}

\section{Risk indicators}

Two principal measures of corporate performance are profit rate and growth rate (Freel 2000; Geroski and Machin 1992; Wynarczyk and Thwaites 1996). Needless to say, there are a number of ways to measure growth rate and profitability which are substantially linked to several variables of operational activities. Several studies have overwhelmingly indicated that effective employee management, along with other strategic measures, can lead to a competitive advantage in the form of a motivated workforce, improved operational and business performance, reduced employee turnover, and improved productivity, which in turn improve the net profit of a firm (Batt 2002; Macduffie 1995; Virdi 2005). Moreover, growth of a business would appear to play an important role in its sustainability in a dynamic business (Barbara et al. 2000). We could, therefore, interpret that dissatisfaction with net profit and in business growth (assuming that the business plan is realistic), as well as significant employee turnover rates, could be the results of inappropriate or inadequate strategic allocation and utilization of resources and that these should be treated as primary indicators of potential problems for an organization. Our research approach, however, was not to verify the measures of these categories. Rather, it tried to identify whether there is any correlation between business growth rate and net profit, and the potential disturbances. The research finds that approximately 32\% of the SMEs are dissatisfied with their existing 'net profit' (of which $10 \%$ are very dissatisfied) and about $40 \%$ are dissatisfied with 'business growth' (of which $10 \%$ are very dissatisfied). On the other hand, 9\% of the organizations are very satisfied with both net profit and business growth. The study also finds that $30 \%$ of SMEs consider the existing 'employee turnover rate' as a substantial impediment to effective business operation, while $43 \%$ indicate the impediment from this factor to be small, and $26 \%$ indicate it to be negligible. These are apparently linked to operational risks of direct or indirect losses due to failures in systems, processes, and people or from external factors. Thus, dissatisfaction level with net profit and in business growth and employee turnover rate is considered as 'risk indicators' for our research. In addition to these three, 11 risk indicators which are linked to operational, occupational, and economic losses are identified from the study. Figure 1 shows the relative position of these risk indicators in terms of their emergence in the systems of the studied SMEs.

\section{Operational disturbances}

The risk indicators have potential linkages with day-today operational disturbances, which degrade business performance and the business environment. In consequence, the disturbances ultimately play a vital role in putting an organization at risk in terms of production, safety, and financial, resulting from both internal and external customer dissatisfaction (Islam 2008). These can lead to a loss of market share and eventually put the 


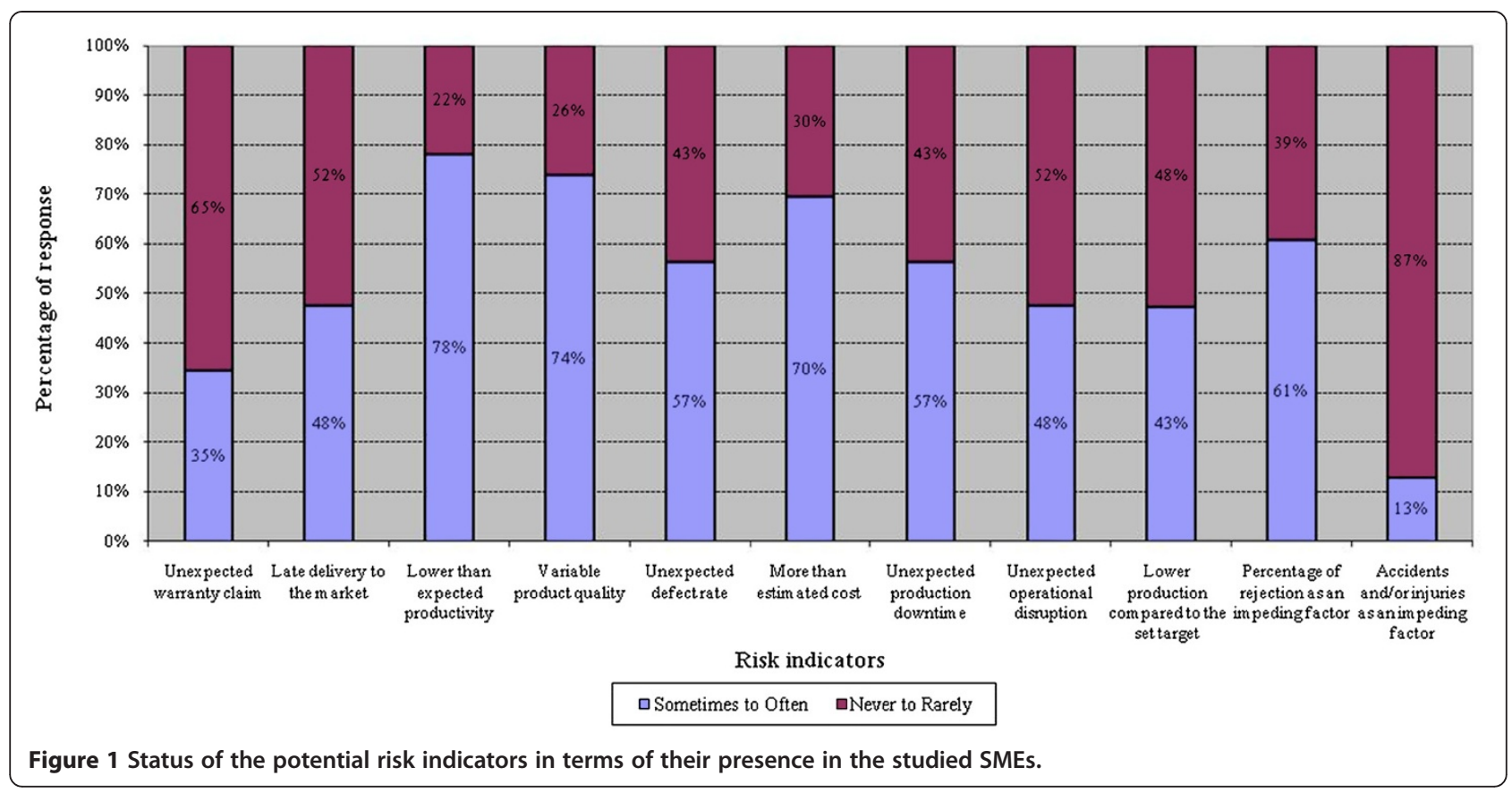

organization out of business, if they are not carefully treated. For this, a thorough investigation was conducted to identify key operational disturbances (in essence, driving risk factors) and their linkage to some risk indicators discussed in the previous section. We have identified a number of notable internal and external operational disturbances, which are summarized in Figures 2 and 3.

Among the internal disturbances, absenteeism, machine malfunction, machine breakdown, and material handling disruption were found to be the most significant disturbances, and unexpected major hazards, unexpected accidents/injuries, and tool shortage were found to be the least significant ones, while the other disturbances were found to fall between these extremes. Among the external disturbances, competition, delayed supply by the regular supplier, and skilled labor shortage were found to be the most significant ones, while financial obstacle was found to be the least significant in terms of their influence on the operational system. However, despite the minimal influence of some disturbances, they were still considered for further analysis to find out their consequential effects.

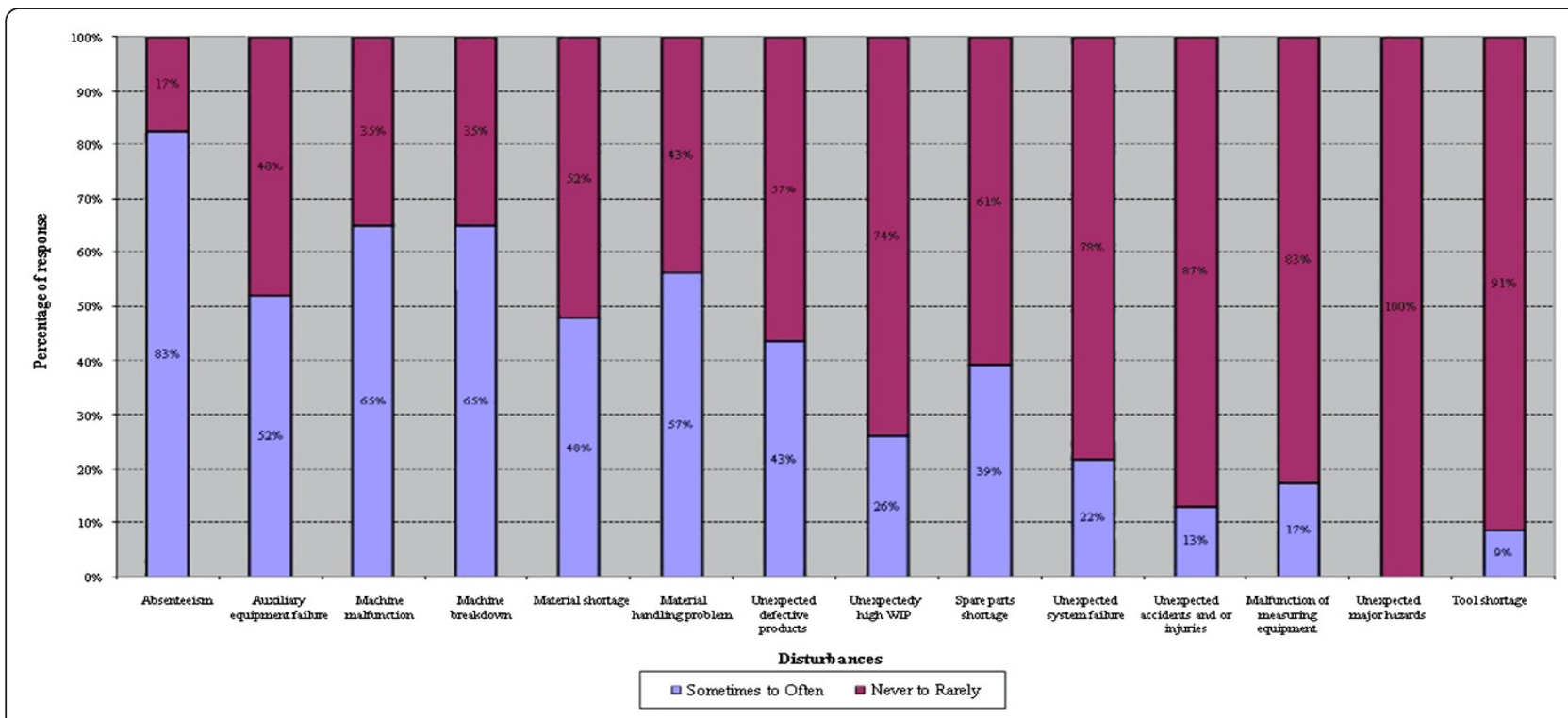

Figure 2 Status of the potential internal disturbances in the studied SMEs. 


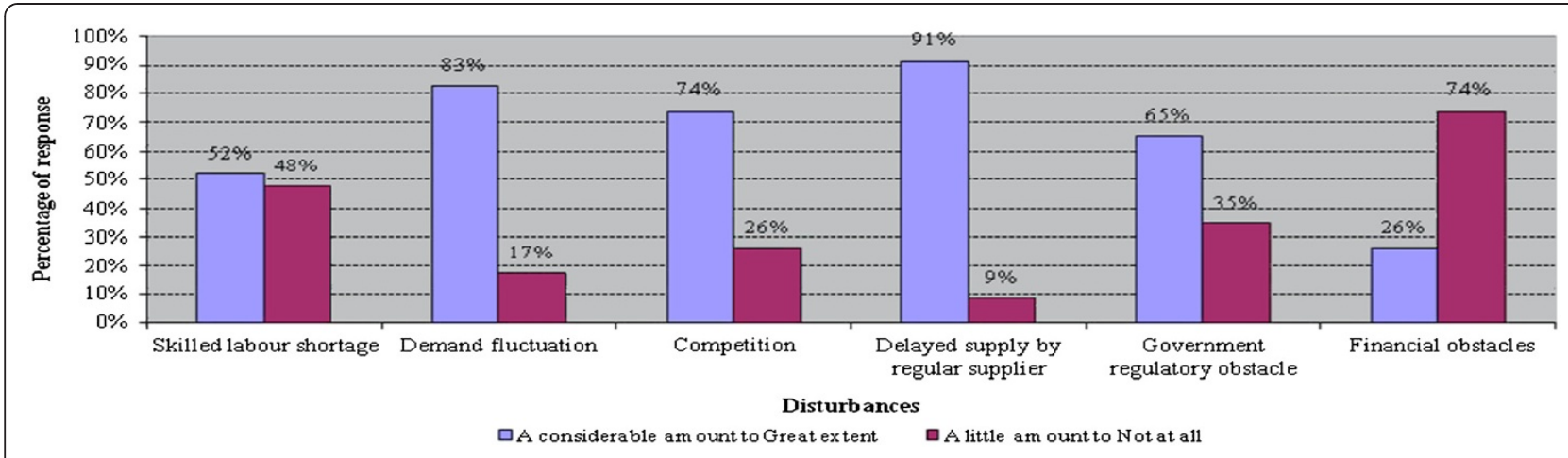

Figure 3 Status of the potential external disturbances in the studied SMEs.

\section{Risk determinants}

All disturbances presented in Figures 2 and 3 were considered for further analysis to determine whether they should be treated as risk determinants. The analysis included some statistical methods of parametric and non-parametric testing such as $t$ test, the Friedman test, and the Spearman correlation coefficient tests (Hinton 2004) at two significant levels: $\alpha=0.01$ (99\% confidence level) and $\alpha=0.05$ (95\% confidence level). The results of the $t$ test are presented in Table 2 .

On the basis of their comparative occurrence in practice, the disturbances are assigned with relative scores. The disturbance which occurs most frequently is assigned with the highest score, while the disturbance which occurs least frequently is assigned with the lowest score. Thus, among the internal disturbances, 'absenteeism' scores the highest number of points, and 'tool shortage' and 'unexpected major hazard' jointly score the lowest.
The relative positions of the internal disturbances, based on their scores, are shown in the second column of Table 3. The final test results (based on Spearman's correlation coefficient, $r_{s}$ ) confirm the positive correlation between internal disturbances and risk indicators; the results are presented in Table 4. Based on the positive correlation of disturbances with a number of risk indicators, scoring is performed. The highest scorer is correlated with a maximum number of risk indicators, while the lowest one is correlated with a minimum number of risk indicators. Thus, all disturbances are assigned with scores and are presented in the third column of Table 3. Finally, on the basis of the product of two scores (one for appearance or occurrence and the other for correlation), final ranking is performed for the risk determinants. The determinant which scores the maximum value is assigned with the highest rank (1), and the determinant which scores the minimum value is assigned with the lowest rank (14). Accordingly, the

Table 2 Results of $\mathbf{t}$ tests with internal disturbances

\begin{tabular}{|c|c|c|c|c|c|c|c|c|c|c|c|c|c|}
\hline & d2 & d3 & d4 & d5 & d6 & d7 & d8 & d9 & d10 & d11 & d12 & d13 & d14 \\
\hline Absenteeism (d1) & $3.213^{* *}$ & $3.026^{* *}$ & $2.621^{* *}$ & $3.346^{* *}$ & $5.724^{* *}$ & $2.421^{*}$ & $3.471^{* *}$ & $4.592^{* *}$ & $7.854^{* *}$ & $5.738^{* *}$ & $6.098^{* *}$ & $11.754^{* *}$ & $10.817^{* *}$ \\
\hline Auxiliary equipment failure (d2) & & -0.264 & 0.190 & 0.711 & 0.886 & -0.549 & 1.283 & $1.899^{*}$ & $2.998^{* *}$ & $3.696^{* *}$ & $3.581^{* *}$ & $6.789^{* *}$ & $6.260^{* *}$ \\
\hline Machine malfunctions (d3) & & & 0.374 & 1.121 & 1.371 & -0.264 & 1.513 & $2.197^{* *}$ & $3.899^{* *}$ & $4.243^{* *}$ & $6.244^{* *}$ & $7.414^{* *}$ & $7.468^{* *}$ \\
\hline Machine breakdown (d4) & & & & 0.514 & 0.753 & -0.537 & 0.983 & 1.274 & $2.913^{* *}$ & $2.731^{* *}$ & $3.366^{* *}$ & $6.249^{* *}$ & $4.136^{* *}$ \\
\hline Material shortage (d5) & & & & & 0.309 & -1.371 & 0.989 & 1.429 & $2.584^{* *}$ & $3.931^{* *}$ & $3.845^{* *}$ & $6.969^{* *}$ & $5.359^{* *}$ \\
\hline Material handling problem (d6) & & & & & & -1.429 & 0.789 & 1.045 & $2.989^{* *}$ & $2.532^{* *}$ & $3.581^{* *}$ & $5.778^{* *}$ & $6.054^{* *}$ \\
\hline Unexpected defective product (d7) & & & & & & & $3.308^{* *}$ & $3.283^{* *}$ & $3.329^{* *}$ & $5.381^{* *}$ & $4.333^{*}$ & $6.875^{* *}$ & $8.125^{* *}$ \\
\hline Unexpected work-in-progress (d8) & & & & & & & & 0.000 & 0.560 & 1.077 & 1.663 & $2.278^{* *}$ & $3.696^{* *}$ \\
\hline Spare parts shortage (dg) & & & & & & & & & 0.783 & $1.899^{*}$ & $2.062^{*}$ & $2.954^{* *}$ & $6.278^{* *}$ \\
\hline Unexpected system failure (d10) & & & & & & & & & & 0.437 & 1.435 & $6.696^{* *}$ & $3.280^{* *}$ \\
\hline Unexpected accidents/injuries (d11) & & & & & & & & & & & 1.208 & $2.249^{*}$ & $3.638^{* *}$ \\
\hline Malfunctions of measuring equipment (d12) & & & & & & & & & & & & 0.711 & $1.986^{*}$ \\
\hline Unexpected major hazard (d13) & & & & & & & & & & & & & 1.295 \\
\hline Tool shortage (d14) & & & & & & & & & & & & & \\
\hline
\end{tabular}

Numbers are the values of $t^{\prime} s ;{ }^{*} p<0.05 ;{ }^{* *} p<0.01$. 
Table 3 Potential risk determinants (internal)

\begin{tabular}{|c|c|c|c|c|}
\hline \multirow[t]{2}{*}{ Risk determinants } & $\begin{array}{l}\text { Scores of the disturbances } \\
\text { based on the distribution of the } \\
\text { frequency of occurrence }(F)\end{array}$ & $\begin{array}{l}\text { Scores of the disturbances } \\
\text { based on their positive correlation } \\
\text { with the risk indicators (C) }\end{array}$ & Total score & $\begin{array}{l}\text { Final ranks of the } \\
\text { risk determinants }\end{array}$ \\
\hline & $\begin{array}{c}(14=\text { highest score } \\
1=\text { lowest score })\end{array}$ & $\begin{array}{c}\text { (14 = highest score } \\
1=\text { lowest score) }\end{array}$ & $(\mathrm{F} \times \mathrm{C})$ & $\begin{array}{l}(1=\text { most important } \\
14=\text { least important })\end{array}$ \\
\hline Absenteeism & 14 & 14 & 196 & 1 \\
\hline Unexpected defective product & 13 & 9 & 117 & 2 \\
\hline Machine malfunctions & 12 & 5 & 60 & 5 \\
\hline Auxiliary equipment failure & 11 & 4 & 44 & 7.5 \\
\hline Material shortage & 9 & 12 & 108 & 3 \\
\hline Material handling problem & 9 & 11 & 99 & 4 \\
\hline Machine breakdown & 9 & 6.5 & 58.5 & 6 \\
\hline Spare parts shortage & 7 & 3 & 21 & 10 \\
\hline Unexpected work-in-progress & 5.5 & 2 & 11 & 12 \\
\hline Unexpected system failure & 5.5 & 8 & 44 & 7.5 \\
\hline Unexpected accidents or injuries & 4 & 10 & 40 & 9 \\
\hline Malfunctions of measuring equipment & 3 & 1 & 3 & 14 \\
\hline Unexpected major hazard & 1.5 & 6.5 & 9.75 & 13 \\
\hline Tool shortage & 1.5 & 13 & 19.5 & 11 \\
\hline
\end{tabular}

relative ranking for all risk determinants is established and is shown in the fifth column of Table 3. According to the final ranking, 'absenteeism' becomes the most important (number 1) risk determinant among the internal disturbances, while 'malfunctions of measuring equipment' becomes the least important one. Similar tests were conducted and relative measures were performed on the external disturbances, the results of which are summarized in the second and third columns of Table 5 .

\section{Discussion and evaluation}

The findings from the mail survey have been presented in the previous section. Most of the findings have strongly been supported by the findings from case studies. Both investigations confirm that there are some

Table 4 Correlation between internal disturbances and risk indicators

\begin{tabular}{|c|c|c|c|c|c|c|c|c|c|c|c|c|c|c|}
\hline & D1 & D2 & D3 & D4 & D5 & D6 & D7 & D8 & D9 & D10 & D11 & D12 & D13 & D14 \\
\hline Absenteeism & $0.67^{* *}$ & IPC & $0.39^{*}$ & IPC & $0.77^{* *}$ & IPC & $0.30^{*}$ & $0.33^{*}$ & $0.40^{*}$ & $0.32^{*}$ & IPC & $0.48^{* *}$ & $0.64^{* *}$ & $0.60^{* *}$ \\
\hline Auxiliary equipment failure & $0.49^{*}$ & IPC & $\mathrm{IPC}$ & $0.47^{*}$ & $0.45^{* *}$ & $0.50^{* *}$ & IPC & NC & $0.31^{*}$ & $\mathrm{NC}$ & NC & IPC & $0.36^{*}$ & IPC \\
\hline Machine malfunctions & $0.44^{*}$ & IPC & IPC & $0.33^{*}$ & IPC & $0.43^{*}$ & $\mathrm{NC}$ & $0.30^{*}$ & IPC & $\mathrm{NC}$ & $0.40^{*}$ & IPC & $0.41^{*}$ & $0.39^{*}$ \\
\hline Machine breakdown & $0.42^{*}$ & IPC & $0.44^{*}$ & IPC & $0.40^{*}$ & IPC & $0.30^{*}$ & IPC & $0.55^{* *}$ & $0.35^{*}$ & $0.51^{* *}$ & NC & IPC & IPC \\
\hline Material shortage & $0.54^{* *}$ & $0.62^{* *}$ & $0.33^{*}$ & $0.40^{*}$ & $0.38^{*}$ & NC & $0.53^{* *}$ & $0.36^{*}$ & $0.51^{* *}$ & $0.35^{*}$ & IPC & IPC & NC & NC \\
\hline Material handling problem & $0.49^{* *}$ & $0.53^{* *}$ & $0.39 *$ & $0.44^{*}$ & $0.61^{* *}$ & IPC & IPC & $0.33^{*}$ & IPC & $0.49^{* *}$ & $0.43^{*}$ & IPC & IPC & IPC \\
\hline Unexpected defective product & $0.36^{*}$ & IPC & IPC & IPC & $0.52^{* *}$ & $\mathrm{NC}$ & $0.47^{* *}$ & NC & NC & $0.56^{* *}$ & $\mathrm{NC}$ & $0.33^{* *}$ & $0.35^{*}$ & $0.45^{* *}$ \\
\hline Unexpected work-in-progress & $\mathrm{IPC}$ & NC & IPC & NC & IPC & IPC & $\mathrm{NC}$ & $0.41^{*}$ & $0.33^{*}$ & IPC & $\mathrm{NC}$ & $0.45^{* *}$ & $\mathrm{IPC}$ & NC \\
\hline Spare parts shortage & $0.35^{*}$ & NC & $0.38^{*}$ & IPC & $0.35^{*}$ & IPC & IPC & NC & $0.51^{* *}$ & NC & $\mathrm{NC}$ & $0.34^{*}$ & $0.38^{*}$ & IPC \\
\hline Unexpected system failure & $0.39^{*}$ & IPC & $0.43^{*}$ & IPC & $0.53^{* *}$ & IPC & $0.36^{*}$ & $\mathrm{NC}$ & NC & $0.57^{* *}$ & $0.40^{*}$ & $\mathrm{NC}$ & $\mathrm{IPC}$ & $0.45^{* *}$ \\
\hline Unexpected accidents/injuries & $0.04^{*}$ & IPC & $0.34^{*}$ & $0.37^{*}$ & $\mathrm{IPC}$ & $0.38^{*}$ & IPC & $0.43^{*}$ & $1.00^{* *}$ & $\mathrm{NC}$ & $0.41^{*}$ & $0.44^{*}$ & $\mathrm{NC}$ & $\mathrm{NC}$ \\
\hline Malfunctions of measuring equipment & IPC & IPC & $\mathrm{NC}$ & $\mathrm{NC}$ & $\mathrm{NC}$ & $\mathrm{NC}$ & $\mathrm{NC}$ & $0.50^{* *}$ & IPC & $\mathrm{NC}$ & $0.52^{* *}$ & IPC & IPC & NC \\
\hline Unexpected major hazard & $0.39^{*}$ & IPC & $0.43^{*}$ & IPC & $0.49^{* *}$ & $0.32^{*}$ & $0.32^{*}$ & $\mathrm{NC}$ & $0.31^{*}$ & $0.45^{* *}$ & $0.41^{*}$ & NC & IPC & NC \\
\hline Tool shortage & $0.48^{*}$ & IPC & $0.34^{*}$ & $0.37^{*}$ & $0.43^{*}$ & $0.50^{* *}$ & IPC & $0.33^{*}$ & $0.37^{*}$ & $\mathrm{NC}$ & IPC & $0.49^{* *}$ & $0.73^{* *}$ & $0.45^{* *}$ \\
\hline
\end{tabular}

Numbers in the boxes are the values of $r_{s}$ IPC, insignificant positive correlation; NC, no correlation; D1, lower than expected productivity; D2, variable product quality; D3, unexpected defect rate; D4, more than estimated cost; D5, unexpected production downtime; D6, unexpected operational disruption; D7, lower production compared to the set target; D8, percentage of rejection at various levels; D9, accidents and/or injuries; D10, late delivery to the market; D11, unexpected warranty claim; D12, employee turnover rate; D13, dissatisfaction level with net profit; D14, dissatisfaction level with business growth; ${ }^{*} p<0.05$; ${ }^{* *} p<0.01$. 
Table 5 Potential risk determinants (external)

\begin{tabular}{|c|c|c|c|c|}
\hline \multirow[t]{2}{*}{ Risk determinants } & $\begin{array}{c}\text { Scores of the disturbances } \\
\text { based on the distributions of the } \\
\text { level of impediments on business (i) }\end{array}$ & $\begin{array}{l}\text { Scores of the disturbances } \\
\text { based on their positive correlation } \\
\text { with the risk indicators (c) }\end{array}$ & Total score & $\begin{array}{l}\text { Final ranking of } \\
\text { the risk determinants }\end{array}$ \\
\hline & $\begin{aligned}(6 & =\text { highest score, } \\
1 & =\text { lowest score })\end{aligned}$ & $\begin{aligned}(6 & =\text { highest score } \\
1 & =\text { lowest score })\end{aligned}$ & $(i \times c)$ & $\begin{array}{c}(1=\text { most important } \\
6=\text { least important })\end{array}$ \\
\hline Delayed supply by the suppliers & 6 & 2.5 & 15 & 2 \\
\hline Demand fluctuation & 5 & 2.5 & 12.5 & 4 \\
\hline Competition & 4 & 4.5 & 18 & 1 \\
\hline Skilled labor shortage & 3 & 4.5 & 13.5 & 3 \\
\hline Government regulations & 2 & 1 & 2 & 6 \\
\hline Financial obstacles & 1 & 6 & 6 & 5 \\
\hline
\end{tabular}

typical internal and external operational disturbances, which expose SMEs to operational risks. Comparative findings from the two investigations are depicted in Figures 4 and 5. The comparison for disturbances is made on an extended scale of 1 to 10 in terms of their frequency of occurrence (for internal disturbances) and of their detrimental effects on operational performance (for external disturbances). Figure 4 shows that both investigations identify 'absenteeism' as the most frequently occurring internal disturbance and 'tool shortage' as the least frequently occurring in the SMEs studied, while the others fall between these two extremes. Figure 5 shows that 'delayed supply by regular suppliers' (very closely followed by 'demand fluctuation' and 'competition') is the most detrimental external disturbance, and 'financial obstacles' is the least detrimental to the SMEs. Both investigations further confirmed a set of risk indicators, which can be used as the consequential effects resulting from the disturbances (Figure 6). These risk indicators are linked to operational, occupational, and economic losses. The findings of both investigations again converge on the same conclusions, in terms of the overall ranking of the disturbances, even though there are slight, statistically insignificant variations in some cases.

The research study reveals that SMEs have, in general, inadequate measures and planned strategies in place to deal with such risk determinants. Thus, the identified set of internal and external risk determinants found from this study will play a vital role in ensuring that SMEs realize the strengths and weaknesses in their ability to cope with the identified internal factors, as well as the threats and opportunities arising from the identified external factors, while assisting them in formulating and implementing strategic measures to deal with the resulting operational risks. It is obvious that some disturbances are more detrimental than others. Moreover, the nature of the disturbance is found to be dynamic and idiosyncratic in nature. The dynamic behavior of a disturbance in different organizational settings and in different time frame leads us to a common understanding that the appearance of a particular disturbance varies from organization to organization and time to time. Moreover, the same disturbance produces different

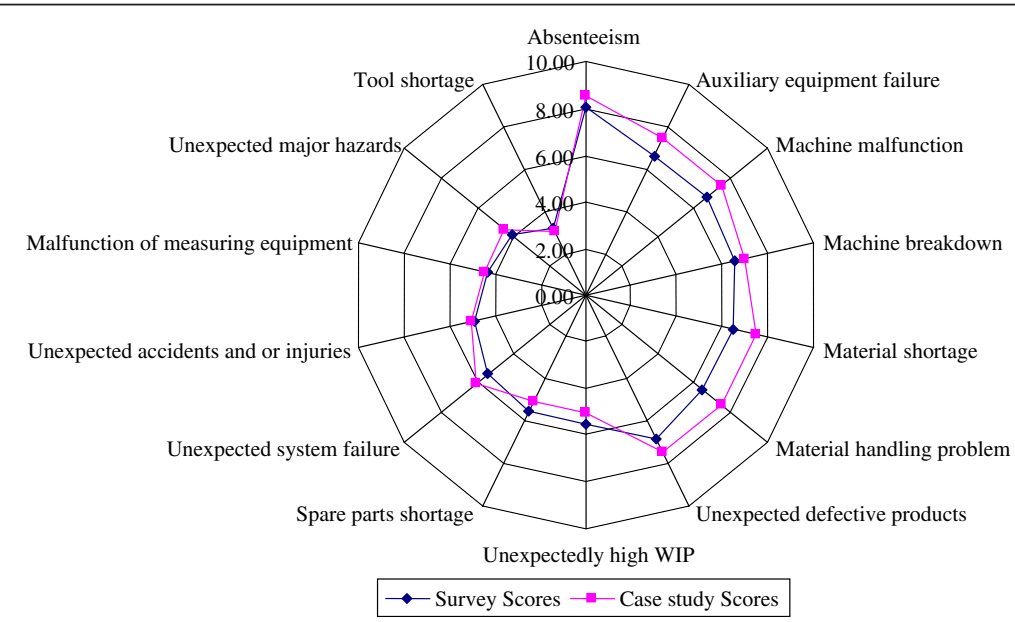

Figure 4 Comparative images between the survey and case study results on internal disturbances. 


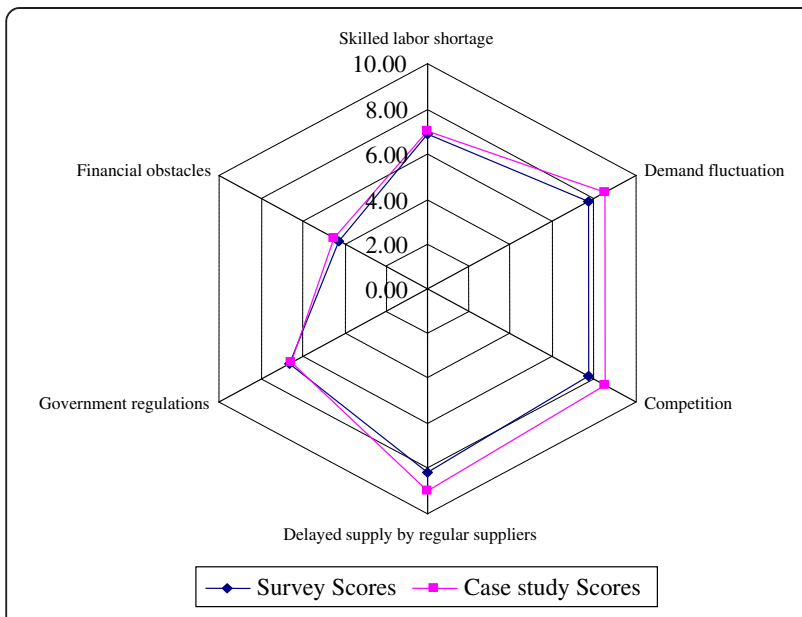

Figure 5 Comparative images between the survey and case study results on external disturbances.

consequential effects to different organizations based on its time of occurrence and the duration of its existence in the system. An organization, therefore, needs to identify the characteristics of the various disturbances and their consequential effects over time, to develop a proactive strategy for managing operational risks.

\section{Conclusions}

An organization is basically a giant network of interconnected nodes. Changes in one part of an organization can affect other parts of the organization with surprising and often negative consequences. The minimization of delays in the system generally becomes an important issue in lean manufacturing. In this context, the optimization of response time to changes in the external environment becomes vital. At the same time, smooth and consistent operational performance in the internal environment is necessary to continue the business in this dynamic business world. Internal and external disturbances to its day-to-day operation put an SME at risk in terms of production, safety, and the business itself. The risks associated with disturbances can be detected by analyzing the negative or detrimental consequential effects, which are identified as risk indicators in the research. We have identified some typical internal and external operational disturbances that need to be considered as risk determinants for SMEs. It is found that some disturbances are positively correlated with a greater number of risk indicators and some with a lesser number of indicators. It is also found that every disturbance is significantly correlated with at least one of the risk indicators. This means that in terms of operational risks, an SME needs to consider all the identified disturbances (risk determinants) in its strategic decisions for managing operational risks successfully.

We find that the majority of the studied SMEs do not have systematic risk management strategies in place. It is discovered that the majority of SMEs used standard hazard identification forms, which comply with the requirements of the Health and Safety in Employment Act in New Zealand (Avery 1993). The current practices in SMEs regarding risk identification relies, almost exclusively, on the documented records of industrial injuries which these forms produce. Near misses are not generally recorded even though this is a requirement of the legislation. Moreover, the identification of root

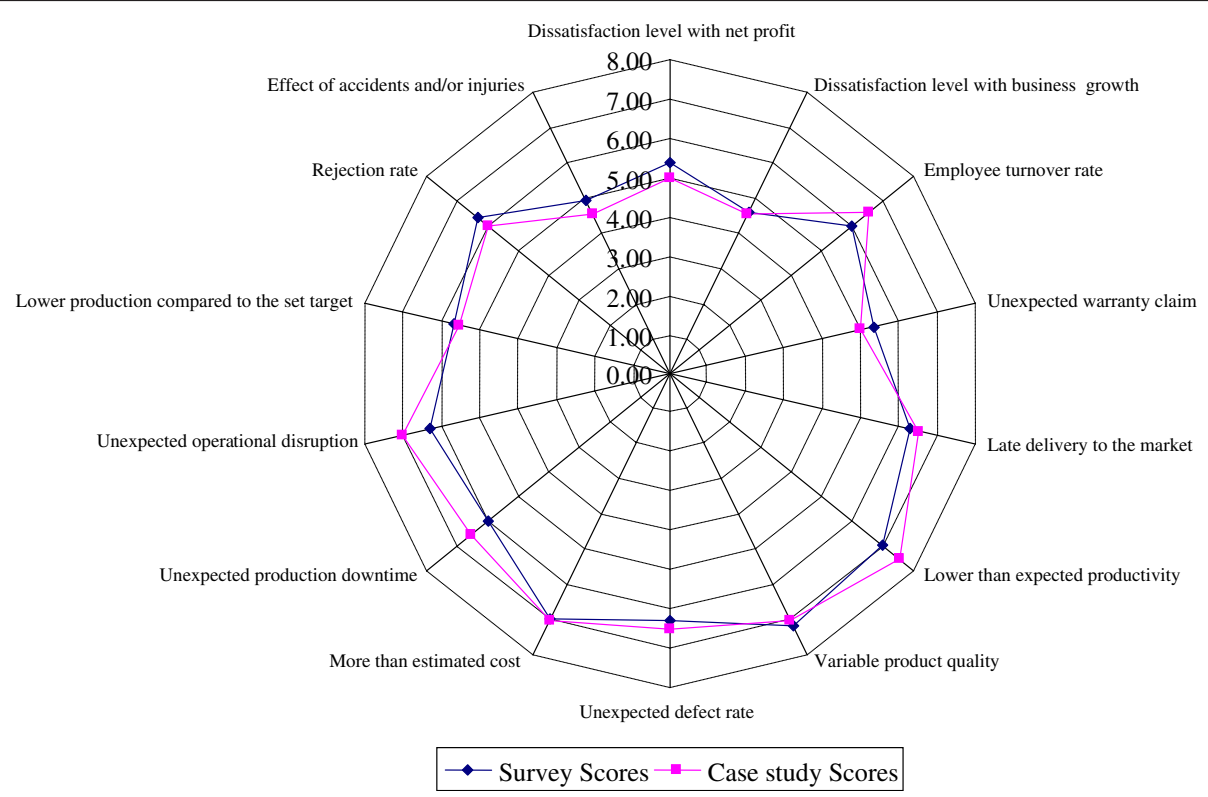

Figure 6 Comparative images between the survey and case study results on risk indicators. 
causes of the risk determinants and their related origins is not practiced in the studied SMEs, and in SMEs where it is practiced to some extent, the flow of information tends to miss many of the relevant personnel. In addition, the disturbance handling systems in these organizations, in terms of data collection, information processing, information sharing, and decision making, are found to be relatively weak and very informal. With regard to the identification of external disturbances, most SMEs do not have assessment criteria in place to measure the consequences, nor have enough information available to help them determine their root causes.

The identified set of internal and external risk determinants should provide a quick reference or benchmark for SMEs. The struggle with the identification of operational risk determinants should be minimized by the identified set of determinants, obtained from a representative sample of SMEs in New Zealand. It is, however, relevant to note that the relative rankings of the identified risk determinants could vary from organization to organization based on their likelihood of occurrence and their impact on business performance. The individual business setting, including current strategic measures, practices, and vulnerability, would play a vital role in developing appropriate strategic plans and actions in each case. While it may be necessary for organizations to add or delete determinants to those identified in this research, depending on their particular situation, they should be able to apply the described methodology to assist them in identifying the risk determinants appropriate to them. In this way, they should be able to identify the extent of the risks associated with the determinants by incorporating the metrics of time, money, and asset loss due to these. In conclusion, the research findings presented in this paper will, hopefully, add to the body of knowledge on good practices in risk management resulting from operational disturbances which can affect SMEs and that may also be useful to both management professionals and researchers in the field of risk management.

\section{Additional file}

Additional file 1: Key questions in the questionnaire for top management and middle and front-line management.

\section{Competing interests}

The authors declare that they have no competing interests.

\section{Authors' contributions}

Dr. MAI designed the research, collected and analyzed the data, and drafted the manuscript. Dr. DT substantially contributed to the conception and design phase, modification of the questionnaires and analysis, and editing of the manuscript critically for its intellectual content. Both authors read and approved the final manuscript.

\section{Authors' information}

Dr. MAI is an associate professor in the Department of Industrial and Production Engineering, Shahjalal University of Science and Technology. He obtained his PhD degree from the University of Auckland, New Zealand, and has been actively doing research for more than 13 years. His principal research activities are in the areas of engineering management including risk management, quality management, and productivity improvement of manufacturing systems. Dr. DT is an associate professor in Engineering Management at the University of Auckland. He gained his PhD degree from the Queens University of Belfast and has been a practicing researcher for over 36 years. As a chartered engineer (C. Eng) and a member of the Institution of Engineering and Technology (IET), his principal research activities are in the areas of manufacturing systems and engineering management. He has been consulting widely with manufacturing and process industries in New Zealand, Australia, and the UK in areas directly related to productivity improvement and process optimization

\section{Author details}

'Department of Industrial and Production Engineering, Shahjalal University of Science and Technology, Sylhet 3114, Bangladesh. ${ }^{2}$ Department of Mechanical Engineering, The University of Auckland, Auckland 1142, New Zealand.

Received: 1 August 2010 Accepted: 3 March 2012

Published: 10 August 2012

\section{References}

Anderson RL, Dunkelberg JS (1990) Entrepreneurship: starting a new business. Harper and Row, New York

Andrews JD, Moss TR (2002) Reliability and risk assessment, 2nd edn. Professional Engineering, London

Avery M (1993) Health \& safety laws at work: key issues. Teemay Consultants, New Zealand

Bahr NJ (1997) System safety engineering and risk assessment: a practical approach. Taylor \& Francis, Washington, DC

Barbara JO, Sandy HS, Allan LR (2000) Performance, firm size, and management problem solving. Journal of Small Business Management 38(4):42-58

Batt R (2002) Managing customer services: human resource practices, quit rates, and sales growth. Academy of Management Journal 45:587-597

Black TR (1999) Doing quantitative research in the social sciences: an integrated approach to research design, measurement and statistics. Sage, Thousand Oaks

Bowman C, Ambrosini V (1997) Using single respondents in strategy research. British Journal of Management 8:119-131

Brewer J, Hunter A (2006) Foundation of multi-method research: synthesizing styles. Sage, Thousand Oaks

Charmaz K (2006) Constructing grounded theory - a practical guide through qualitative analysis. Sage, Thousand Oaks

Dennis WJ Jr (2003) Raising response rates in mail surveys of small business owners results of an experiment. Journal of Small Business Management 41 (3):287-295

Denzin NK (1989) The research act: a theoretical introduction to sociological method, 3rd edn. Prentice Hall, Englewood Cliffs

Freel MS (2000) Do small innovating firms outperform non-innovators? Small Business Economics 14(3):195-210

Geroski P, Machin S (1992) Do innovating firms outperform non-innovators? Business Strategy Review Summer 3:79-90

Gibson B, Cassar G (2005) Longitudinal analysis of relationships between planning and performance in small firms. Small Business Economics 25(3):207-222

Glaser BG, Strauss AL (1980) The discovery of grounded theory - strategies for qualitative research, 11 th printing. Aldine, New York

Hartcher J, Allan H, Scott H (2003) Perceptions of risks and risk management in small firms. Small Enterprise Research: The Journal of SEAANZ 11(2):71-92 Hinton PR (2004) Statistics explained, 2nd edn. Routledge, New York

Hoffman K, Milady P, Bessant J, Perren L (1998) Small firms' R\&D, technology and innovation in the UK: a literature review. Technovation 18(1):39-55

Islam MA (2008) Risk management in small and medium-sized manufacturing organization in New Zealand, PhD Thesis, Department of Mechanical Engineering. The University of Auckland

Islam MA, Tedford JD, Haemmerle E (2006) Proceedings of the 2006 IEEE International Conference on Management and Innovation and Technology, 
Singapore. In: Strategic risk management approach for small and mediumsized manufacturing enterprises (SMEs) — a theoretical framework, 2nd edn. Singapore, IEEE, pp 694-694

Islam MA, Tedford JD, Haemmerle E (2008) Managing operational risks in smalland medium-sized enterprises (SMEs) engaged in manufacturing-an integrated approach. International Journal of Technology, Policy and Management 8(4):420-441

Jeynes J (2002) Risk management: 10 principles. Butterworth-Heinemann, Oxford

Jick TD (1979) Mixing qualitative and quantitative methods: triangulation in action. Administrative Science Quarterly 24:602-610

Khan Fl, Abbasi SA (1998) Techniques and methodologies for risk analysis in chemical process industries. Journal of Loss Prevention in the Process Industries 11:261-277

Luis EQ, Felisa MC, Serge W, Christopher OB (1999) A methodology for formulating a business strategy in manufacturing firms. International Journal of Production Economics 60-61:87-94

Macduffie JP (1995) Human resource bundles and manufacturing performance: organizational logic and flexible production systems in the world auto industry. Industrial and Labor Relations Review 48:197-221

Martie-Louise V (2006) Strategy-making process and firm performance in small firms. Journal of Management and Organization 12:209-222

Milan J (2000) An assessment of risk and safety in civil aviation. Journal of Air Transport Management 6:43-50

Mills J, Platts K, Gregory M (1995) A framework for the design of manufacturing strategy process: a contingency approach. International Journal of Operations and Production Management 15(4):17-49

Ministry of Economic Development (2003) SMEs in New Zealand: structure and dynamics. Ministry of Economic Development, Wellington

Ministry of Economic Development (2004) SMEs in New Zealand: structure and dynamics. Ministry of Economic Development and Statistics New Zealand, Wellington

Mitala A, Pennathurb A (2004) Advanced technologies and humans in manufacturing workplaces: an interdependent relationship. International Journal of Industrial Ergonomic 33:295-313

Monica PB, John RW (1999) HEDOMS-human errors and disturbance occurrence in manufacturing systems: toward the development of an analytical framework. Human Factors and Ergonomics in Manufacturing 9(1):87-104

Monostori L, Szelke E, Kadar B (1998) Management of changes and disturbances in manufacturing systems. Annual Reviews in Control 22:85-97

Mushtaq F, Chung PWH (2000) A systematic Hazop procedure for batch processes, and its application to pipeless plants. Journal of Loss Prevention in the Process Industries 13:41-48

Pearson AM, Dutson TR (1995) HACCP in meat, poultry and fish processing. Blackie Academic and Professional, New York

Pettigrew AM, Whipp R, Rosenfeld R (1989) Competitiveness and the management of strategic change process: a research agenda. In: Francis $A$, Tharakan M (eds) The competitiveness of European industry: country, policies and company strategies. Routledge, London, p 36

Scudder GD, Hill CA (1998) A review and classification of empirical research in operations management. Journal of Operations Management 16:91-101

Seastroma JW, Peercy RL Jr, Johnson GW, Sotnikov BJ, Brukhanov N (2004) Risk management in international manned space program operations. Acta Astronautica 54:273-279

Strupczewski A (2003) Accident risks in nuclear-power plants. Applied Energy 75:79-86

Tixier J, Dusserre G, Salvi O, Gaston D (2002) Review of 62 risk analysis methodologies of industrial plants. Journal of Loss Prevention in the Process Industries 15:291-303

Toulouse G (2002) Accident risks in disturbance recovery in an automated batchproduction system. Human Factors and Ergonomics in Manufacturing 12 (4):383-406

Virdi AA (2005) Risk management among SMEs-executive report of discovery research. The Consultation and Research Centre of the Institute of Chartered Accountants in England and Wales, London

Waring A, Glendon Al (1998) Managing risk: critical issues for survival and success into the 21st century, 1st edn. International Thomson Business, London

Watson ML, Vuuren JJ (2002) Entrepreneurship training for emerging SMEs in South Africa. Journal of Small Business Management 40(2):154-161

Wynarczyk P, Thwaites A (1996) The financial performance of innovative small firms in the UK. In: Oakey R (ed) New technology based firms in the 1990s, 11th edn. Paul Chapman, London
Yin RK (1994) Case study research, 2nd edn. Sage, London

Zacharakis AL, Meyer GD, DeCastro J (1999) Differing perceptions of new venture failure: a matched exploratory study of venture capitalists and entrepreneurs. Journal of Small Business Management 37(3):1-14

doi:10.1186/2251-712X-8-12

Cite this article as: Islam and Tedford: Risk determinants of small and medium-sized manufacturing enterprises (SMEs) - an exploratory study in New Zealand. Journal of Industrial Engineering International 2012 8:12.

\section{Submit your manuscript to a SpringerOpen ${ }^{\circ}$ journal and benefit from:}

- Convenient online submission

- Rigorous peer review

- Immediate publication on acceptance

- Open access: articles freely available online

- High visibility within the field

- Retaining the copyright to your article

Submit your next manuscript at $\gg$ springeropen.com 